\title{
Relationships of loneliness and mobile phone dependence with Internet addiction in Japanese medical students
}

\author{
Satoko Ezoe ${ }^{1^{*}}$, Masahiro Toda ${ }^{2}$ \\ ${ }^{1}$ Shimane University, Health Service Center Izumo, Shimane, Japan; ${ }^{*}$ Corresponding Author: satoezoe@med.shimane-u.ac.jp \\ ${ }^{2}$ Department of Pharmacology, Osaka Dental University, Osaka, Japan
}

Received 25 July 2013; revised 12 August 2013; accepted 19 August 2013

Copyright (C) 2013 Satoko Ezoe, Masahiro Toda. This is an open access article distributed under the Creative Commons Attribution License, which permits unrestricted use, distribution, and reproduction in any medium, provided the original work is properly cited.

\begin{abstract}
We investigated factors contributing to Internet addiction in 105 Japanese medical students. The subjects were administered by a self-reporting questionnaire designed to evaluate demographic factors, Internet addiction, loneliness, healthrelated lifestyle factors, depressive state, patterns of behavior, and mobile phone dependence. Results of multivariate logistic regression analysis indicated that loneliness and mobile phone dependence were positively related to degree of addiction. Our findings suggest that Internet addiction is associated with loneliness and mobile phone dependence in Japanese students.
\end{abstract}

Keywords: Internet Addiction; Mobile Phone Dependence; Loneliness; Depression; Medical Students

\section{INTRODUCTION}

The Internet rapidly developed and came into widespread use in Japan in the mid-1990s, and has since become an established part of daily life. In 2011, there were 96 million users, which correspond to a penetration rate of about $80 \%$ [1]. While this new information and communication technology resource is convenient and popular, various social issues have arisen, including changes in interpersonal relationships, leaks of private information, Internet swindles, excessive use, and even dependence.

In the Diagnostic and Statistical Manual of Mental Disorders (DSM) [2], two concepts are used to define aspects of dependence in regard to substance abuse; be- havioral and physical. In behavioral dependence, substance-seeking activities and related evidence of pathological use patterns are emphasized, whereas physical dependence refers to the physical effects of multiple episodes of substance use. In definitions stressing physical dependence, ideas of tolerance or withdrawal appear in the classification criteria [2,3], and the term addiction is nearly the same concept as dependence. Griffiths reported elements of Internet addiction, such as tolerance, withdrawal symptoms, and recurrence [4], while psychological dependence (addiction) on information technology (IT), such as the Internet and mobile phonesalso referred to as habituation-is characterized by excessive use and an intermittent craving for IT-related activities.

According to Young, Internet addiction is defined as excessive time spent on Internet-related activities, an increasing tolerance to the effects of being online, unpleasant feelings when off-line, and denial of associated problematic behaviors [5]. Previous studies showed that Internet addiction is associated with loneliness [6-20], depression [10,11,19-25], poor self-esteem [7,10,26], shyness [27], and low life satisfaction $[15,16]$. However, few multivariate studies have been conducted to investigate the correlation of Internet addiction with loneliness, health-related lifestyle factors, patterns of behavior, depressive state, and mobile phone dependence. In particular, because mobile phone use for IT purposes has become widespread in Japan, it is considered necessary to examine the relationship between Internet addiction and mobile phone dependence.

In previous studies, we found that mobile phone dependence is associated with unhealthy lifestyle factors [28-30], extrovert or neurotic personality traits [29], maternal affectionate constraint in childhood [31], Type A behavior traits [30], and depression [30], which might be 
related to Internet addiction. On the other hand, few reports have been presented regarding the relationship between Internet addiction with personal computer use and mobile phone dependence. In the present study, we utilized multivariate logistic regression analysis to examine the association of demographic characteristics, loneliness, health-related lifestyle factors, depressive state, patterns of behavior, and mobile phone dependence with Internet addiction.

\section{MATERIALS AND METHODS}

\subsection{Subjects}

We recruited 139 freshmen university students from the Faculty of Medicine at Shimane University in Japan. After the protocol received the approval of the institute's review board and informed consent was obtained from each participant, the subjects filled out a set of self-reporting questionnaires designed to evaluate Internet addiction, health-related lifestyle factors, loneliness, depressive state, behavior patterns, and mobile phone dependence. Answers from 105 of the respondents (40 males, 65 females) who accessed the Internet with a personal computer and properly completed all the questionnaire items were statistically analyzed. The mean $( \pm \mathrm{SD})$ ages for the males were $19.3 \pm 2.0$ and for the females were $18.7 \pm 1.0$ years.

\subsection{Internet Addiction}

Internet addiction was evaluated using Young's Internet Addiction Test (IAT) [5], a self-rating questionnaire that consists of 20 items. Each response was scored on a Likert scale $(1,2,3,4,5)$, with the scores then summed to provide a quantitative overall Internet addiction score ranging from 20 to 100 . Higher scores indicated a greater level of addiction. According to Young's criteria, respondents with scores greater than 40 were categorized as addict (including probable addict).

\subsection{Loneliness}

Loneliness was evaluated using the UCLA Loneliness Scale (Version 3) [32]. This is a 20-item self-report inventory measured using a Likert scale $(1,2,3,4)$ with a total score ranging from 20 to 80 and high scores indicating a high level of loneliness.

\subsection{Depressive State}

Depressive state was assessed using the Beck Depression Inventory-II (BDI-II) [33], a self-rating questionnaire that consists of 21 items with a total score ranging from 0 to 63 . Higher scores indicate greater levels of depression. The reliability and usefulness of the Japanese version of the BDI-II have been confirmed [34]. Our subjects were categorized as having either no or minimal, or mild or greater depression based on this score (cutoff point 13/14) [33].

\subsection{Behavior Patterns}

Type A behavior patterns vary according to culture and nationality [35]. Therefore, we assessed patterns of behavior using the Tokai University Type A Pattern Scale $[35,36]$, which was designed for a Japanese population. The scale consists of 11 items with a total score ranging from 0.25 to 98.75 . Our subjects were categorized as having either a Type A or Type B behavior pattern, with those scoring greater than 43.1 points placed in the Type A category [36].

\subsection{Health-Related Lifestyle}

In the Alameda Country Study performed in the United States, 7 health practices were shown to be significantly related to physical health status and, subsequently, mortality rate [37]. Based on that study and after taking into consideration differences in cultural backgrounds, we revised the list of 7 practices to 8 items for Japanese respondents [38,39].

We awarded higher points for responses that indicated better lifestyle choices in regard to health, with the overall rating for each respondent derived from 8 lifestyle items; smoking habit, drinking habit, daily consumption of breakfast, appropriate daily duration of sleep and work, regular physical activity, appropriate levels of stress, and a nutritionally balanced diet. Each item had multiple answers (2 - 6 each), and the answers were dichotomized into a "good" or "not good" health practice [30]. Scores from the 8 "good" items were totaled to provide an index of cumulative personal health practices, or Health Practice Index (HPI). Respondents with $6-8$ points were allocated to the good and those with $0-5$ points to the poor category $[30,40]$.

\subsection{Mobile Phone Dependence}

Mobile phone dependence was evaluated using the Mobile Phone Dependence Questionnaire (MPDQ) [41], a self-rating questionnaire that consists of 20 items. Each response was scored on a Likert scale $(0,1,2,3)$. Likert scores for each item were then summed to provide a quantitative overall mobile phone dependence score ranging from 0 to 60 . Higher scores were considered to indicate greater dependence.

\subsection{Statistical Analysis}

Univariate and subsequent multivariate logistic regression analyses were applied to identify possible associations between Internet addiction and each factor (demographic characteristics, loneliness, depressive state, 
health-related lifestyle, patterns of behavior, mobile phone dependence). All variables with a $p$ value $<0.2$ in univariate analysis were included in the forward stepwise multivariate analysis (likelihood ratio) after age adjustment. Statistical significance was set at $\mathrm{p}<0.05$ and the confidence interval was $95 \%$.

\section{RESULTS}

Table 1 shows the results for each questionnaire. Scores for Internet addiction ranged from 20 to 87 (mean 38.4 ), while the frequency of addict students was $42.9 \%$. Table 2 shows personal characteristics related to the Internet addiction category.

Univariate logistic regression results revealed a statistically significant relationship between Internet addiction and university department $(\mathrm{OR}=2.53, \mathrm{p}<0.05)$, depressive state $(\mathrm{OR}=4.33, \mathrm{p}<0.005)$, mobile phone dependence $(\mathrm{OR}=1.05, \mathrm{p}<0.05)$, and loneliness $(\mathrm{OR}=1.12, \mathrm{p}$ $<0.001$ ) (Table 3). In addition to those variables, mode of residence and pattern of behavior (variables with $p$ value $<0.2$ ) were included in the age-adjusted multivariate logistic regression analysis. Using a forward stepwise procedure (likelihood ratio), non-significant variables were removed from the multivariate model until only significant $(\mathrm{p}<0.05)$ variables remained. As a result, loneliness $(\mathrm{OR}=1.13, \mathrm{p}<0.001)$ and mobile phone dependence $(\mathrm{OR}=1.07, \mathrm{p}<0.05)$ were found to be independently associated with Internet addiction (Table 3 ).

\section{DISCUSSION}

A principal finding of this study was a significant positive correlation between loneliness and Internet addiction. Many studies have reported this finding [6-19], while Bozoglan et al. [16] and Ceyhan \& Ceyhan [19] also noted that loneliness was the most important variable associated with Internet addiction. In examinations of the initial hypothesis regarding the relationship between loneliness and Internet use [8], Internet use was shown to cause loneliness by isolating individuals from the real world and deprive them of a sense of a connection with real-world contacts $[8,17]$. On the other hand,

Table 1. Mean scores and ranges for examined factors.

\begin{tabular}{lcc}
\hline & Mean \pm S.D. & Range \\
\hline Internet Addiction Test (IAT) & $38.4 \pm 13.5$ & $20-87$ \\
$\begin{array}{l}\text { Mobile Phone Dependence Questionnaire } \\
\text { (MPDQ) }\end{array}$ & $26.6 \pm 9.2$ & $6-54$ \\
UCLA Loneliness Scale & $39.7 \pm 9.5$ & $22-64$ \\
Beck Depression Inventory-II (BDI-II) & $8.7 \pm 8.6$ & $0-36$ \\
Type A Pattern Scale of Tokai University & $38.9 \pm 8.7$ & $17.5-66.5$ \\
Health Practice Index (HPI) & $5.5 \pm 1.1$ & $3-8$ \\
\hline
\end{tabular}

Table 2. Subject characteristics and Internet addiction category.

\begin{tabular}{ccc}
\hline & Non-addicts \% (n) & Addicts \% (n) \\
\hline Gender & $57.5(23)$ & $42.5(17)$ \\
Male & $56.9(37)$ & $43.1(28)$ \\
Mode of residence & & \\
Solitary & $54.3(50)$ & $45.7(42)$ \\
Other & $76.9(10)$ & $23.1(3)$ \\
Department & & \\
Medicine & $47.5(28)$ & $52.5(31)$ \\
Nursing & $69.6(32)$ & $30.4(14)$ \\
Behavior type & & $57.7(15)$ \\
Type A & $42.3(11)$ & $38.0(30)$ \\
Type B & $62.0(49)$ & \\
Depression & & $34.2(27)$ \\
Absent & $65.8(52)$ & $69.2(18)$ \\
Present & $30.8(8)$ &
\end{tabular}

the cognitive-behavioral model for pathological Internet use (PIU) [42] suggests that loneliness predisposes an individual to PIU. This latter hypothesis was then confirmed by a longitudinal study that did not find a negative impact of Internet use on loneliness level [11]. Lonely individuals might experience pleasure online because of the increased potential for companionship and belonging $[9,17]$. In this sense, the Internet may provide an ideal social environment for lonely individuals to interact with other people [17], thus they might be more prone to Internet addiction.

In the present study, there was a significant positive correlation between mobile phone dependence and Internet addiction when using a personal computer. Mobile phone dependence and Internet addiction have common characteristics in regard to two factors; excessive use and an intermittent craving to engage in IT-related activities. Therefore, it was suggested that students with higher traits of mobile phone dependence would show greater levels of Internet addiction. Meanwhile, the Internet is available for access by mobile phones as well as personal computers. In particular, smartphones, with their easy-to-access Internet features, have come into widespread use in recent years, with a penetration rate in Japan of about $30 \%$, according to a survey carried out by Ministry of Internal Affairs and Communications in 2012 [43]. Although we examined the relationship between mobile phone dependence and Internet addiction when using personal computers in the present study, additional examinations are needed to clarify the problem of Internet addiction in individuals using smartphones.

Our multivariate logistic regression analysis results showed that depressive state was not significantly related 
Table 3. Univariate and multivariate logistic regression analyses to identify factors associated with Internet addiction.

\begin{tabular}{|c|c|c|c|c|c|c|}
\hline \multirow[b]{2}{*}{ Candidate factors } & \multicolumn{3}{|c|}{ Univariate analysis } & \multicolumn{3}{|c|}{ Multivariate analysis ${ }^{*}$} \\
\hline & $\begin{array}{c}\text { Crude } \\
\text { odds ratio }\end{array}$ & $95 \%$ Confidence interval & $P$ value & $\begin{array}{l}\text { Adjusted } \\
\text { odds ratio }\end{array}$ & $95 \%$ Confidence interval & $P$ value \\
\hline Gender ( 1 , male; 0 , female $)$ & 0.98 & $0.44-2.17$ & 0.954 & & & \\
\hline Health-related lifestyle ( 1 , good; 0 , poor) & 0.82 & $0.38-1.78$ & 0.612 & & & \\
\hline Mode of residence ( 1 , solitary; 0 , other) & 2.80 & $0.72-10.84$ & 0.136 & & & \\
\hline Department ( 1 , medicine; 0 , nursing) & 2.53 & $1.13-5.69$ & 0.025 & & & \\
\hline Behavior type (1, Type A; 0, Type B) & 2.23 & $0.91-5.48$ & 0.082 & & & \\
\hline Depression (1, present; 0 , absent) & 4.33 & $1.67-11.25$ & 0.003 & & & \\
\hline Mobile Phone Dependence Questionnaire & 1.05 & $1.00-1.10$ & 0.039 & 1.07 & $1.01-1.12$ & 0.017 \\
\hline UCLA Loneliness Scale & 1.12 & $1.00-1.18$ & 0.000 & 1.13 & $1.07-1.19$ & 0.000 \\
\hline
\end{tabular}

*Using a forward stepwise procedure, non-significant factors were removed from the model until only significant $(\mathrm{p}<0.05)$ factors remained.

to Internet addiction. Casale and Fioravanti reported that loneliness was a significant predictor of PIU, whereas depression was not [17], which is consistent with our findings. Furthermore, Caplan suggested that social wellbeing (loneliness) played a greater role than psychological health (depression) in predicting generalized PIU [44]. Thus, loneliness rather than depression might be associated with Internet addiction.

Our study has some limitations. The cross-sectional nature of this examination limits conclusions that can be reached regarding the causal relationships of Internet addiction with loneliness and mobile phone dependence. Also, the effects of extrovert or neurotic personality traits and other sociodemographic variables, such as academic achievements and economic condition, were not analyzed. Furthermore, our questionnaire did not include items specific to smartphones and, as mentioned above, further study is needed to examine Internet addiction with the use of smartphones. In addition, we did not take into account the types of Internet services accessed by our subjects, such as e-mail, information, shopping, games, adult websites, chat rooms, blogging, and SNS. Finally, the sample size was small and all subjects were students of the same university, thus a general population cohort is not represented. Additional examinations with larger and more varied populations are required.

In summary, our findings suggest that university students with feelings of loneliness and mobile phone dependence are prone to have a higher level of Internet addiction. To identify individuals at high risk of Internet addiction, it is important to consider those factors.

\section{REFERENCES}

[1] Ministry of Internal Affairs and Communications (2011) Information \& communication statistics database, 2011. http://www.soumu.go.jp/johotsusintokei/satistics/statistics 05.html

[2] American Psychiatric Association (2000) Diagnostic and statistical manual of mental disorders-DSM-IV-TR. 4th Edition, American Psychiatric Association, Washington DC.

[3] Sadock, B.J. and Sadock, V.A. (2007) Kaplan \& Sadock's synopsis of psychiatry: Behavioral science/clinical psychiatry. 10th Edition, Lippincott Williams \& Wilkins, Philadelphia.

[4] Griffiths, M. (1998) Internet addiction: Does it really exist? In: Gackenbach, J., Ed., Psychology and the Internet, Academic Press, San Diego, 61-73.

[5] Young, K.S. (1998) Caught in the net. John Wiley \& Sons, New York.

[6] Amichai-Hamburger, Y. and Ben-Artzi, E. (2003) Loneliness and Internet use. Computers in Human Behavior, 19, 71-80. doi:10.1016/S0747-5632(02)00014-6

[7] Ghassemzadeh, L., Shahraray, M. and Moradi, A. (2008) Prevalence of internet addiction and comparison of internet addicts and non-addicts in Iranian high schools. Cyberpsychology and Behavior, 11, 731-733. doi: $10.1089 / \mathrm{cpb} .2007 .0243$

[8] Kraut, R., Patterson, M., Lundmark, V., Kiesler, S., Mukopadhyay, T. and Scherlis, W. (1998) Internet paradox: A social technology that reduces social involvement and psychological well being? American Psychologist, 53, 1017-1031. doi:10.1037/0003-066X.53.9.1017

[9] Morahan-Martin, J. and Schmacher, P. (2000) Incidence and correlates of pathological Internet use among college students. Computers in Human Behavior, 16, 13-29. doi:10.1016/S0747-5632(99)00049-7

[10] Shaw, L.H. and Gant, L.M. (2002) In defense of the Internet: The relationship between internet communication and depression, loneliness, self-esteem and perceived social support. Cyberpsychology and Behavior, 5, 157-171. doi:10.1089/109493102753770552

[11] Takahira, M., Ando, R. and Sakamoto, A. (2008) Effect of internet use on depression, loneliness, aggression and preference for internet communication: A panel study with 10- to 12-year-old children in Japan. International Journal of Web Based Communities, 4, 302-318. doi:10.1504/IJWBC.2008.019191

[12] Hardie, E. and Tee, M.Y. (2007) Excessive Internet use. The role of personality, loneliness and social support 
networks in Internet addiction. Australian Journal of Emerging Technologies and Society, 5, 34-47.

[13] Moody, E.J. (2001) Internet use and its relationship to loneliness. Cyberpsychology and Behavior, 4, 393-401. doi:10.1089/109493101300210303

[14] Morahan-Martin, J. and Schmacher, P. (2003) Loneliness and social uses of the Internet. Computers in Human Behavior, 19, 659-671. doi:10.1016/S0747-5632(03)00040-2

[15] Stepaninikova, I., Nie, N.H. and He, X. (2010) Time on the Internet at home, loneliness, and life satisfaction: Evidence from panel time-diary data. Computers in Human Behavior, 26, 329-338. doi:10.1016/j.chb.2009.11.002

[16] Bozoglan, B., Demirer, V. and Sahin, I. (2013) Loneliness, self-esteem, and life satisfaction as predictors of Internet addiction: A cross-sectional study among Turkish university students. Scandinavian Journal of Psychology, 54, 313-319.

[17] Casale, S. and Fioravanti, G. (2011) Psychosocial correlates of internet use among Italian students. International Journal of Psychology, 46, 288-298. doi:10.1080/00207594.2010.541256

[18] Nalwa, K. and Anand, A. (2003) Internet addiction in students: A cause of concern. Cyberpsychology and Behavior, 6, 653-656. doi:10.1089/109493103322725441

[19] Ceyhan, A. and Ceyhan, E. (2008) Loneliness, depression, and computer self-efficacy as predictors of problematic Internet use. Cyberpsychology and Behavior, 11, 699-701. doi: $10.1089 / \mathrm{cpb} .2007 .0255$

[20] Özcan, N.K. and Buzlu, S. (2007) Internet use and its relation with the psychosocial situation for a sample of university students. Cyberpsychology and Behavior, 10, 767-772.

[21] Caplan, S.E. (2003) Preference for online social interaction: A theory of problematic Internet use and psychosocial well-being. Communication Research, 30, 625-648. doi: $10.1177 / 0093650203257842$

[22] Kim, K., Ryu, E., Chon, M., et al. (2006) Internet addiction in Korean adolescents and its relation to depression and suicidal ideation: A questionnaire survey. International Journal of Nursing Studies, 43, 185-192. doi:10.1016/j.ijnurstu.2005.02.005

[23] Park, S. (2009) The association between internet use and depressive symptoms among South Korean adolescents. Journal for Specialists in Pediatric Nursing, 14, 230-238. doi:10.1111/j.1744-6155.2009.00191.x

[24] Caplan, S.E., Williams, D. and Yee, N. (2009) Problematic Internet use and psychosocial wellbeing among MMO players. Computers in Human Behavior, 25, 13121319. doi:10.1016/i.chb.2009.06.006

[25] Morgan, C. and Cotte, S.R. (2003) The relationship between Internet activities and depressive symptoms in a sample of college freshmen. Cyberpsychology and Behavior, 6, 133-142. doi:10.1089/109493103321640329

[26] Armstrong, L., Phillip, J. G. and Saling, L.L. (2000) Potential determinants of heavier internet usage. International Journal of Human-Computer Studies, 53, 537-550. doi:10.1006/ijhc. 2000.0400
[27] Chak, K. and Leung, L. (2004) Shyness and locus of control as predictors of internet addiction and internet use. Cyberpsychology and Behavior, 7, 559-570.

[28] Toda, M., Monden, K., kubo, K. and Morimoto, K. (2006) Mobile phone dependence and health-related lifestyle of university students. Social Behavior and Personality, 34, 1277-1284. doi:10.2224/sbp.2006.34.10.1277

[29] Ezoe, S., Toda, M., Yoshimura, K., Naritomi, A., Den, R. and Morimoto, K. (2009) Relationships of personality and lifestyle with mobile phone dependence among female nursing students. Social Behavior and Personality, 37, 231-238. doi:10.2224/sbp.2009.37.2.231

[30] Toda, M. and Ezoe, S. (2013) Multifactorial study of mobile phone dependence in medical students: Relationship to health-related lifestyle, Type A behavior, and depressive state. Open Journal of Preventive Medicine, 3, 99-103. doi:10.4236/ojpm.2013.31012

[31] Toda, M. and Ezoe, S., Nishi, A., Goto, M. and Morimoto, K. (2008) Mobile phone dependence of female students and perceived parental rearing attitudes. Social Behavior and Personality, 36, 765-770. doi:10.2224/sbp.2008.36.6.765

[32] Russell, D.W. (1996) UCLA loneliness scale (version 3): Reliability, validity, and factor structure. Journal of Personality Assessment, 66, 20-40. doi:10.1207/s15327752jpa6601_2

[33] Beck, A.T., Steer, R.A. and Brown, G.K. (1996) Manual for the Beck Depression Inventory-II. Psychological Corporation, San Antonio.

[34] Kojima, M., Furukawa, T.A., Takahashi, H., Kawai, M., Nagaya, T. and Tokudome, S. (2002) Cross-cultural validation of the Beck Depression Inventory-II in Japan. Psychiatric Research, 110, 291-299. doi:10.1016/S0165-1781(02)00106-3

[35] Hosaka, T. and Tagawa, R. (1987) The Japanese characteristic of Type A behavior pattern. The Tokai Journal of Experimental and Clinical Medicine, 12, 287-303.

[36] Hosaka, T. and Tagawa, R. (1989) The coronary-prone behavior pattern among Japanese: Its comparison with Type A behavior pattern. Japanese Journal of Psychosomatic Medicine, 29, 527-536.

[37] Belloc, N.B. and Breslow, L. (1972) Relationship of physical health status and health practices. Preventive Medicine, 1, 409-421. doi:10.1016/0091-7435(72)90014-X

[38] Kusaka, Y., Kondou, H. and Morimoto, K. (1992) Healthy lifestyles are associated with natural killer cell activity. Preventive Medicine, 32, 602-615. doi:10.1016/0091-7435(92)90068-S

[39] Ezoe, S. and Morimoto, K. (1994) Behavioral lifestyle and mental health status of Japanese factory workers. Preventive Medicine, 23, 98-105. doi:10.1006/pmed.1994.1014

[40] Toda, M., Makino, H., Kobayashi, H. and Morimoto, K. (2007) Health-related lifestyle and patterns of behavior related to health effects of leisure travel. Social Behavior and Personality, 35, 287-294.

doi:10.2224/sbp.2007.35.3.287 
[41] Toda, M., Monden, K., Kubo, K. and Morimoto, K. (2004) Cellular phone dependence tendency of female university students. Japanese Journal of Hygiene, 59, 383-386. doi:10.1265/ijh.59.383

[42] Davis, R.A. (2001) A cognitive-behavioral model of pathological Internet use. Computers in Human Behavior, 17, 187-195. doi:10.1016/S0747-5632(00)00041-8
[43] Ministry of Internal Affairs and Communications (2012) Information \& Communication Statistics Database.

[44] Caplan, S.E. (2002) Problematic internet use and psychosocial well-being: Development of a theory-based cognitive behavioral measurement instrument. Computers in Human Behavior, 18, 553-575. doi:10.1016/S0747-5632(02)00004-3 